\title{
Study on Value Characteristics of Traditional Village and Its Protection Strategy
}

\author{
Chengxin Zhang
}

\author{
South China University of Technology, Tianhe District, Guangzhou, China, 510640 \\ hunter2011@foxmail.com
}

Keywords: Traditional village; Cultural Heritage; Protection.

\begin{abstract}
As is known to all, the protection and utilization of ancient villages are involved in very wide range of problems and those problems are very complicated. In this paper, we firstly elaborate the basic characteristics and value composition of traditional villages, including scientific value, architectural value, artistic value, etiquette value, social value, historical value and spiritual value. Then from the perspective of cultural features, natural landscape, historic relic and intangible heritage, we propose some strategies for the protection of traditional villages.
\end{abstract}

\section{Introduction}

Along with the irreversible trend of urbanization, people are yearning for city life, moving to the city, leading to the decline of rural population and construction. Meanwhile, traditional villages are historical product of social development. However, the traditional villages are facing a severe challenge, and the living situation of ancient villages in China is not optimistic. Therefore, to carry out scientific protection and deal with be relationship between Tourism development and cultural heritage protection has become a critical issue.

\section{Value Characteristics of Traditional Villages}

Basic Characteristics. Traditional villages are relatively independent regional societies in which social activities and social relations occurred. Traditional villages are the result of human activities and natural environment interactions in a specific historical period, so they reflect the economic, political, and cultural characteristics of the society at that time.

(1) Natural environment. Natural environment is composed of mountains, water, land, climate, biology, geology and other factors. In terms of the space environmental characteristics and sites of ancient village, they are generally very particular about the adaptation of nature, that is because the ancients believed that man is part of nature and they y attach great importance to the site of village. E.g. Jiangnan is impressed with water villages; Huizhou is famous with the odd landscapes; while in northwest region, the unique national environment of cave dwellings reflects the local landscape features.

(2) Humanistic environment. Important factors in the formation of characteristic traditional villages are inseparable from geographic and ethnic wisdom. Buildings, streets, facilities and other components constitute the humanistic environment of the ancient villages. The architectural style is the essence of ancient village landscape, and is also a typical representative of the ancient village culture.

(3) Social environment. Factors constituting social environment include economic, folk culture, religion, etc. Vast majority of Chinese villages are located in separate areas with backward economic, inconvenient transportation and isolated environment.

Value Composition. As important resources of cultural tourism, value of traditional villages is mainly reflected in cultural heritage, which includes scientific value, architectural value, artistic value, etiquette value, social value, historical value and spiritual value, as shown in Fig. 1: 


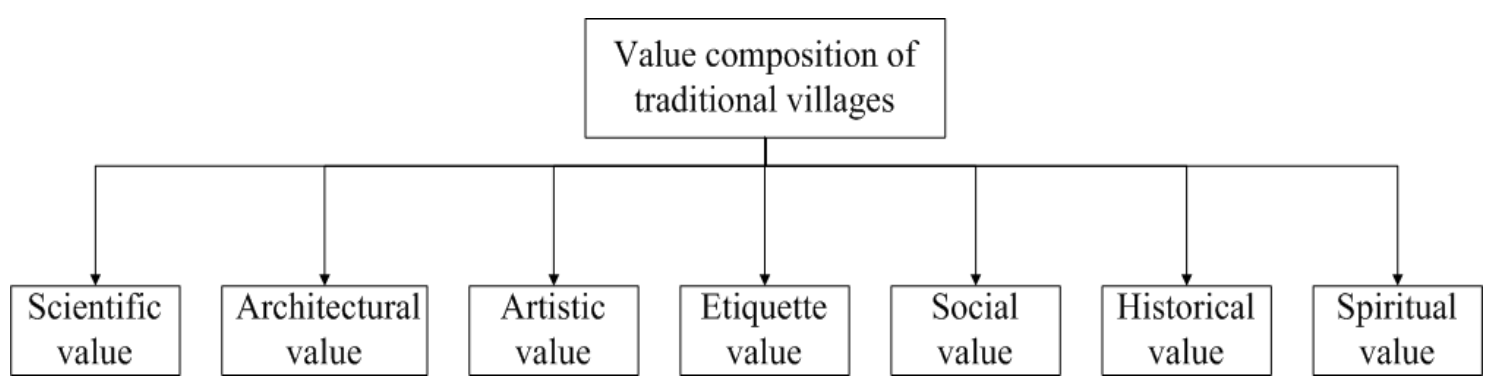

Fig. 1. Value composition of tradition villages

(1) Scientific value. With the foundation formed by the traditional villages, including natural environment, geography and climate, taking full account of the merits of these resources, it can provide the scientific basis for the sustainable development of the traditional villages.

(2) Architectural value. Traditional villages are typical landscape-culture-ecology settlement. Local architectural culture is the best carrier of history and culture. Houses and monuments in traditional villages carry significant architectural value.

(3) Artistic value. The essence of the traditional settlement is the artistic inspiration of life, which is often reflected in the construction, customs, etc. The artistic connotation of the traditional village is a kind of plain and simple expression.

(4) Etiquette value. Whether in terms of location and layout of settlement, or construction of settlement, the traditional villages have deep hierarchy system, which reflects the influence of the effect of etiquette on settlement daily life.

(5) Social value. Traditional villages are a relatively closed community, or collective. Residential houses are private space, but community environment must have a public space, meeting the communication needs for residents.

(6) Historical value. Traditional villages are history of precipitation, and are also specific historical and cultural heritage. No matter how big the change, we should pay attention to the preservation of history and culture.

(7) Spiritual value. Spiritual value of traditional villages is reflected in residents' sense of identity and belonging, which will form a strong spiritual emotion. When physically and mentally tired, residents always think of their own home. Mountains, rivers, and childhood playmate at hometown are lingering, and these are the expression of Homecoming desire. Meanwhile, tourists seek the heart of ancient village through the emotional release and experience.

Overall speaking, the historical value of traditional villages lie in their landscape tourism value, economic value, emotional value and art value, including natural beauty, human beauty, architectural beauty and the vicissitudes beauty as well. Traditional villages integrate rich and unique history together.

\section{Protection Strategies of Traditional Villages}

Protection of Historical and Cultural Features. (1) Overall protection of spatial pattern. The protection of traditional villages should pay attention to the protection of the traditional settlement space and environment, that is, follow the overall spatial pattern, and focus on the protection of the historical features of traditional villages. Historical and cultural protected areas in traditional villages are generally entireties composed of streets, courtyards, construction, landscaping and other elements of the physical environment and the composition of the intangible environmental factors.

(2) Hierarchical protection of the sub-regions. For the protection of traditional settlement space and environment, the key point is the implementation of a hierarchical protection measures. Generally, the protection area is divided into three parts: the main protection zone for protecting and repairing, construction control zone for local transformation and renewal, environmental coordination zone for development and construction.

(3) Organic and dynamic sustainable protection. Due to historical changes, traditional villages are often composed of scattered, interrupted, non-continuous nodes and fragments. Should carry out 
organic and dynamic sustainable protection, and adhere to the combination of dynamic and static protection, for protection, adjustment and reconstruction of historical and cultural protected areas. Moreover, should make effort to encourage the generate public to participate in and enhance their awareness of protection.

Protection of Natural Landscape. (1) Protection of natural ecology. Traditional villages are closely related to the natural environment, including Mountains, water, soil, vegetation, climate, etc. Early in 1994, famous architectural experts Peng Yigang ever elaborate the impact of the natural environment on traditional villages form. It can be said that, in the history of our country, the location of every traditional village is a comprehensive choice of the natural elements. Different forms of the natural environment breeds different traditional villages, and meanwhile, differences in natural environment also affect building layout, form, villagers living habits and folk customs in the villages. So the natural ecology and geography deserve to cause our attention to be protected.

(2) Construction planning and control. For the elements of natural environment in main protection zone, construction control zone and environmental coordination zone, take corresponding measures to ensure construction planning and control. Meanwhile, adjust and optimize the industry structure in the traditional villages, to adapt to the needs of the times, thus create a harmonious coexistence of the traditional village landscape and features.

Protection of Historical Relic. (1) Conservation oriented and rational use. Protect the authenticity of monuments, and reserve its surrounding historical environment information as well. For ancient buildings, should coordinate their overall pattern and the relationship with the surrounding environment, and make great effort to save the endangered cultural relics. In addition, make rational use of the traditional buildings, and correctly deal with the relationship between traditional architecture protection and tourism development, to protect and develop the cultural relics and the environment.

(2) Protection of residents' traditional lifestyle. The environment that traditional villages situated in and residents' dailylife is an organic part of the traditional architecture. Its protection must adhere to the "people-oriented", that is, not only improve the historical environment of the architectures, but also improve the living conditions of the residents, and correctly deal with the relationship between the development of living standards of the villagers and the protection of traditional architecture.

Protection of Intangible Heritage. (1) Protection of material carrier and human space. Intangible heritage needs to be visible by means of a certain carrier, so we should strengthen the protection of intangible cultural heritage material carriers and their living environment. Intangible heritage is a lively culture, and its heritage is closed to people, so in addition to the heritage itself, we should also protect its inheritor, and provide space for cultural heritage.

(2) Establish intangible heritage information platform. Compared to tangible cultural heritage, intangible cultural heritage is more dispersed, and the information recording work is more difficult. So far, there is no perfect information platform for intangible heritage protection, so network digital platform is required to be establish, to publicize and record the intangible cultural heritage, and provide an sharing platform for communication, learning and information acquisition for people.

\section{References}

[1] W. Tao, H.Y. Chen, J.Y. Lin. Spatial form and spatial cognition of traditional village in syntactical view: A case study of Xiaozhou Village, Guangzhou. Acta Geographica Sinica, 2013, 68(2):209-218.

[2] M.T. Liu, L.M. Tang. Case-based Research on Traditional Village Ecology and Sustainable Development. Value Engineering, 2012.

[3] Xiao-He L I, Lan S R, Yun Y U, et al. Study on the Red-brick Traditional Village's Landscape Elements and Analysis its Influencing Factors in Fujian and Taiwan Area. Journal of Fujian Normal University, 2014. 
[4] Zhao X. Order Deconstruction and Value Embodies of Traditional Village Culture. Journal of Anhui Agricultural Sciences, 2011.

[5] Zhao R, Zhen S I. Research on Landscape Protection of Traditional Village Cultural. Heilongjiang Agricultural Sciences, 2013.

[6] Mo H. Culture Tropism and Value Judge about Traditional Village Building in Nanning. Chinese \& Overseas Architecture, 2011. 